\title{
Sensory Attributes and Consumer Acceptability of 12 Microgreens Species
}

\author{
Francesco Caracciolo ${ }^{1,2}\left(\mathbb{D}\right.$, Christophe El-Nakhel ${ }^{1}$, Maria Raimondo ${ }^{3}$, Marios C. Kyriacou ${ }^{4}(\mathbb{D}$, \\ Luigi Cembalo ${ }^{1, *(\mathbb{D})}$, Stefania De Pascale ${ }^{1}$ a and Youssef Rouphael ${ }^{1, *(\mathbb{D})}$ \\ 1 Department of Agricultural Sciences, University of Naples Federico II, 80055 Portici, Italy; \\ francesco.caracciolo@unina.it (F.C.); christophe.elnakhel@unina.it (C.E.-N.); depascal@unina.it (S.D.P.) \\ 2 Alliance of Bioversity International and CIAT, HQ, via dei Tre Denari 472/a, 00054 Rome, Italy \\ 3 Department of Law, Economics, Management and Quantitative Methods, University of Sannio, \\ Piazza Arechi II, 82100 Benevento, Italy; raimondo@unisannio.it \\ 4 Department of Vegetable Crops, Agricultural Research Institute, 1516 Nicosia, Cyprus; \\ m.kyriacou@ari.gov.cy \\ * Correspondence: cembalo@unina.it (L.C.); youssef.rouphael@unina.it (Y.R.)
}

Received: 8 June 2020; Accepted: 16 July 2020; Published: 19 July 2020

\begin{abstract}
Microgreens are gaining increasing recognition among consumers, acclaimed for their freshness and health promoting properties associated with densely fortified secondary metabolites. These immature greens enhance human diet and enrich it with sharp colors and flavors. While numerous species are being tested for agronomic and nutritional suitability, consumer acceptance of appearance, texture, and flavor is critical for the microgreens' marketplace success. This study investigates whether sensory attributes and visual appearance affect consumer preference for microgreens and their willingness to consume them. By means of a consumer test, the sensory attributes of 12 microgreens species were evaluated, wherein a partial least squares structural equation model was developed to link sensorial attributes to willingness to eat the product. The results showed that although visual appearance of the microgreens was largely appreciated, consumer acceptance overall was mainly determined by flavor and texture. In particular, the lower the astringency, sourness, and bitterness, the higher the consumer acceptability of microgreens. Among the 12 examined species, mibuna and cress scored the lowest acceptance by consumers, while Swiss chard and coriander were the most appreciated, being therefore good candidates to be introduced in Western country markets. In addition, both Swiss chard and coriander have been identified by previous literature as good dietary source of phenolic antioxidants.
\end{abstract}

Keywords: consumer preferences; consumer test; PLS-SEM; experimental economics study; vegetable confetti; functional food; emerging food; sensory characteristics; acceptability

\section{Introduction}

Microgreens, also known as 'vegetable confetti', consist of tender immature greens of wild species, herbs, grains, or vegetables, harvested upon the emergence of the first pair of true leaves [1]. Microgreens are analogous in size to sprouts but are eaten without the roots and require additional days to thrive and acquire larger, colored, and flavor-rich leaves [2] under light conditions. Despite their immaturity, microgreens are stamped with sharp flavors, vivid colors, tender textures, and a great pack of phytonutrients [3-6]. Such captivating sensory attributes have bestowed microgreens a distinguished spot among chef's resources for adorning soups, sandwiches, and drinks [5,6], and earned them a place in "organic farming" stores [2]. Based on sensory and health criteria, countless species are used for the production of microgreens including commercial and local varieties, which belong 
to the following botanical families: Amarillydaceae, Amaranthaceae, Apiaceae, Asteraceae, Brassicaeae, Cucurbitaceae, Fabaceae, Lamiaceae, Oxalidaceae, Poaceae, Polygonaceae, and Portulacaceae [1,3-5,7,8].

Microgreens are also regarded as fresh "super foods" $[4,9,10]$ due to their innate fortification with plant secondary metabolites [9,11-13]. Additionally to carotenoids, ascorbic acid, phylloquinone, $\gamma$-tocopherols, and phenolic compounds, microgreens are also a source of macro and micro-minerals. Such nutritive and functional values enhance human diet and prevent a range of common diseases $[4,9,10,12,14]$. Indeed, microgreens enclose a greater load of essential phytonutrients compared to their mature counterparts $[3,4,6,10,13]$. Suchlike dense phytochemical composition has garnered the attention of nutrition researchers $[6,15]$ and gained them prevalence among food technologists, urban farmers, and consumers [15]. As public concern about environmental and nutritional aspects of food production has recently arisen $[16,17]$, consumers are orienting their purchasing behavior toward healthier and environmentally friendlier food products [18-20].

Major components aside from nutritional values dictate consumer acceptance of a food product, such as sensory attributes (i.e., appearance, texture, and flavor) [21]. Appearance dominates consumer choice, while other attributes sustain future purchases [4-6,11,22]. Microgreens offer a palette of colors (i.e., green, yellow, red, crimson, or multicolor), flavors (i.e., neutral, slightly sour, spicy, or bitter), and texture (i.e., juicy, crunchy, or regular) [4]. Humans' organoleptic system allows for the perception of taste and olfactory sensations, and hand over the knowledge about the sensory attributes [5]. Sensory attributes are interconnected with the chemical composition of the product and its acceptability; for instance, the phenolic content is tightly associated with microgreens' astringency, sourness, bitterness, and sweetness attributes [11]. In fact, mixing microgreens with salads is a smart strategy to meliorate the quality and appearance of food without compromising the overall taste [23].

To date, several studies have examined how sensory attributes and visual appearance influence consumer perception towards microgreens per se $[5,8,11,24]$ while others held comparative studies at different maturity stages [25-29]. Altogether, numerous microgreens species are still not assessed for their sensory attributes and acceptance. This current paper aims to examine whether sensory attributes and visual appearance affect consumer preferences and modality for microgreens, and their "Willingness To Consume it" (WTC as product acceptability). Based on the aforementioned, the sensory attributes of 12 microgreens species were appraised through an untrained consumer test. Based on the collected information, a partial least squares structural equation model was developed to link sensorial attributes to consumer willingness to consume it, as consumer preferences will drive the future of the microgreens market $[30,31]$.

\section{Materials and Methods}

\subsection{Genetic Material and Climate Chamber Conditions}

Based on organoleptic and nutritional properties, 12 microgreens species were assessed for their sensory attributes and acceptability: amaranth, coriander, cress, green basil, komatsuna, mibuna, mizuna, pak choi, purple basil, purslane, Swiss Chard, and tatsoi. The scientific name, cultivar, producing company, and the growing cycle of the 12 microgreens species are presented in Supplementary Table S1. The different seeds were sown on different days in order to synchronize the harvest in two fixed successive days, which was based on the emergence of the first two true leaves.

The sowing densities were the ones adopted by Kyriacou et al. [9,12]. The experiment was conducted in the experimental farm of the University of Naples Federico II, Naples, Italy, in a controlled walk-through climate chamber (Process-C5, Spagnol srl, Treviso, Italy) $(7.0 \times 2.1 \times 4.0 \mathrm{~m} ; \mathrm{W} \times \mathrm{H} \times$ D). High-pressure sodium lamps were the source of light, providing $420 \mu \mathrm{mol} \mathrm{m}^{-2} \mathrm{~s}^{-1}$ at canopy level, through a $12 / 12 \mathrm{~h}$ photoperiod. Day/night temperatures and relative humidity were set at $24 / 18 \pm 1{ }^{\circ} \mathrm{C}$ and $60 \% / 70 \%$, respectively. Microgreens species were grown in trays $(56 \times 37 \times 5.5 \mathrm{~cm}$ : $\mathrm{W} \times \mathrm{L} \times \mathrm{D})$ filled with peat moss substrate $\left(\mathrm{pH} 6.3\right.$ and electrical conductivity $0.2 \mathrm{dS} \mathrm{m}^{-1}$; Special 
Mixture, Floragard Vertriebs-GmbH, Oldenburg, Germany) and fertigated daily with a quarter-strength modified Hoagland solution described in detail in Kyriacou et al. [15].

Following the same protocol, all microgreens' samples were harvested in the laboratory, by cutting it just above the substrate level through the mean of a sterilized scissors, and then washed in mineral water. Once dried manually in a salad spinner, each participant received the same quantity of microgreens to test. All species at harvest are illustrated in Figure 1.
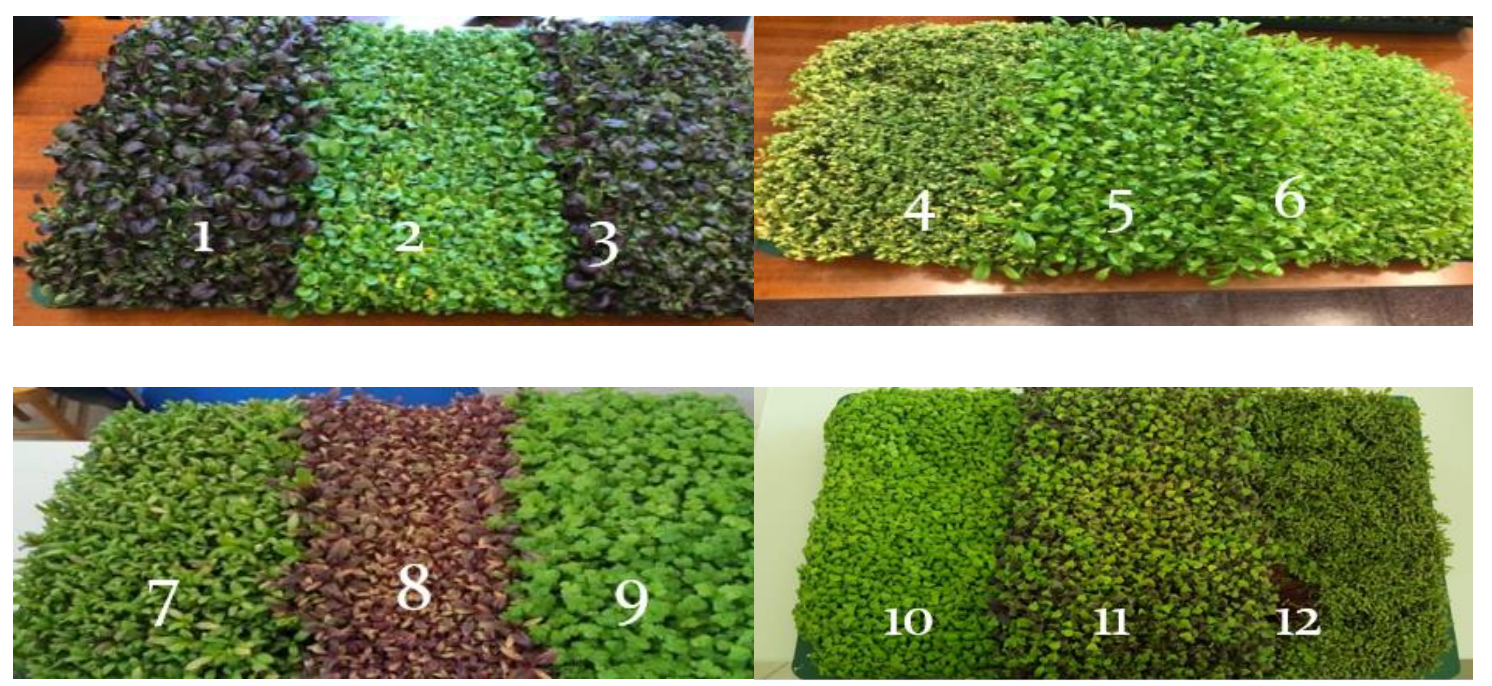

Figure 1. Optical images of the evaluated microgreens species (1. Komatsuna; 2. Tatsoi; 3. Pak choi; 4. Cress; 5. Mibuna; 6. Mizuna; 7. Swiss chard; 8. Amaranth; 9. Coriander; 10. Green basil; 11. Purple basil; 12. Purslane).

\subsection{Consumers Sample}

A sample of 54 untrained volunteers were recruited among students of the Department of Agricultural Sciences, University of Naples Federico II in Naples, Southern Italy. The test was performed in Spring 2018 in a controlled environment, namely in the experimental economics laboratory. Participants were asked to test the 12 microgreens species in order to assess the role of visual appearance and sensory attributes in influencing microgreens' acceptability. The sample size satisfied the requirements set by Resurreccion [32] recommendations. Participants were $59.25 \%$ females and $40.75 \%$ males, with an average age of 23 years ( \pm 3.8 ), with a mode value of 20 years (around $20 \%$ of the sample) and a median value of 22 years.

\subsection{Settings and Procedure of the Consumer Test}

A total of five-assessment sessions were carried out, while the overall experiment was completed in two consecutive days. Three sessions were carried out in the first day with six species of microgreens belonging to the botanical family of Brassicaceae (i.e., komatsuna, tatsoi, pak choi, mizuna, mibuna, and cress). The microgreens harvested at the moment were presented to 30 participants (10 per session); the remaining two sessions were completed on the following day, where 24 participants (12 per session) assessed the remaining six microgreens species (i.e., amaranth, green basil, purple basil, coriander, purslane, and Swiss chard).

The consumer test protocol was the following:

1. Each participant was identified with an ID number to guarantee her/his anonymity. Before starting the consumer test, a brief usable definition of the sensory attributes was provided as well as the explanation of the intensity scale to ensure that all the consumers were able to successfully participate to the tasting session that lasted $30 \mathrm{~min}$ on average. 
2. The experimenter was served at the same time but on different plates, the six species of microgreens (without providing any sort of information).

3. Participants tasted separately the six microgreens following a randomized order. Then, for each genotype they were asked to assess the intensity of the following sensory attributes: sweetness, aroma, astringency, bitterness, grassy, heat, sourness, and texture, using 15-cm labelled magnitude scales (LMS), where 0 means "not perceived at all" and 15 means "perceived very well". Moreover, respondents had to rate their acceptability of the microgreens, regarding appearance, texture, flavor, and overall liking, ranging from $0=$ "Bad" to $15=$ "Excellent" (Table 1). The specific sensory attributes as well as the acceptability categories were selected following a previous consumer test on microgreens carried out by Xiao et al. [11]. Between samples, participants were instructed to pause for $60 \mathrm{~s}$, eat unsalted crackers, and drink water to cleanse their palate.

4. Finally, socio-demographic information (e.g., gender, age) of participants were collected.

Table 1. Sensory attributes and acceptability items collected during the consumer test. The 12 microgreens were assessed by means of nine sensory attributes and four acceptability items and using 15-cm labelled magnitude scales (LMS).

\begin{tabular}{cc}
\hline Sensory Attributes & Scale of Sensory Attributes \\
\hline Sweetness & \\
Aroma & \\
Astringency & \\
Bitterness & Scale: $0=$ not perceived at all, $15=$ perceived very well \\
Grassy & \\
Heat & \\
Sourness & Scale of Acceptability Items \\
Texture & \\
Acceptability & Scale: $0=$ Bad, $15=$ Excellent \\
\hline Acceptability of appearance & \\
Acceptability of flavor & \\
Acceptability of texture & \\
Acceptability of overall eating quality &
\end{tabular}

\subsection{Statistical Analysis}

Once the data was collected, several statistical analyses were performed to identify consumer preferences and WTC (acceptability) of microgreens. Firstly, a one-way ANOVA followed by a Tukey post-hoc test were performed to determine if sensory attributes and WTC were significantly different among the microgreens species. An Exploratory Factor Analysis (EFA) was also implemented for synthetizing the information given on the eight sensory attributes considered in the consumer test (sweetness, aroma, astringency, bitterness, grassy, heat, sourness, and texture). In more detail, the EFA using orthogonal (Varimax) rotation was carried out to identify preliminarily the most relevant underlying sensorial dimensions (or latent constructs) and to reduce the dimensionality of data, by exploiting the correlations among the sensory attributes [33].

Based on the EFA output, a partial least squares structural equation model (PLS-SEM) was developed in line with the algorithm provided by Wold [34] and Lohmöller [35] to assess if and how sensory attributes influence consumer acceptability, including the role of visual appearance. The PLS-SEM method is becoming an important multivariate technique for analyzing consumer preferences and buying behavior in both observational and experimental settings [36-40]. PLS-SEM firstly estimates the latent constructs' scores and then estimates path coefficient and correlation among the construct [41]. More specifically, the PLS-SEM can be used for modelling the relationships among both latent and single-item observed variables. The PLS-SEM is defined "partial" since the algorithm estimates the coefficients for the partial ordinary least square regression models in both measurement 
(or outer) and structural (or inner) models. The latter displays the relationship between the constructs, while the measurement model is used for evaluating the relationship between the single variables (in our case the sensory attributes) and the latent construct [42]. Analytically, the PLS-SEM algorithm consists of three sequential stages $[35,43,44]$. Firstly, the scores of latent variables were estimated. Secondly, the obtained scores were used to estimate measurement model parameters (weights/loading). Finally, in the third stage, structural model parameters (so called path coefficients) were estimated using the ordinary least squares method. According to several authors, the PLS-SEM algorithm attains better statistical capability especially with small sample size and with data not normally distributed $[41,45,46]$. Once the measurement and structural models are specified, the composite reliability is used to evaluate the internal consistency of the construct measures. The convergent and discriminant validity of the construct were assessed. The convergent validity is achieved when each item has outer loadings above 0.7 and when each average variance extracted (AVE) of the construct is equal to 0.5 or higher. The AVE measures the variance of the indicators explained by the construct. The PLS-SEM model was considered in the present study to analyze if and how specific sensory attributes affect consumer preferences for microgreens. All the statistical analyses were carried out by using Stata 16 (Stata Corp LP, College Station, TX, USA).

\section{Results}

\subsection{Sensory Attributes and Acceptability}

Table 2 reports for all microgreens species the mean value and its standard error for each sensory attribute. ANOVA and Tukey post-hoc test revealed that, except for the acceptability for texture, the mean value of sensory attributes considered in this study was significantly different among microgreens.

For the intensity attributes, "Sweetness" scored significantly higher $(5.9 \pm 1.1)$ for Swiss chard, while the "Aroma" was highly perceived in coriander and amaranth ( $13 \pm 0.6$ and $12.2 \pm 0.7$, respectively) without significant differences among tatsoi, green basil, Swiss chard, and purple basil species. The lowest value of "Aroma" (3.4 \pm 0.8$)$ was expressed for purple basil cultivar. The latter also showed the lowest mean value of "Astringency" (3.0 \pm 0.9$)$ that reached the highest value $(7.5 \pm 0.9)$ in mibuna and cress. Moreover, both mibuna and cress were perceived as the most bitter species $(10.0 \pm 0.8$; $9.0 \pm 0.9$, respectively), thus showing the largest mean difference with respect to Swiss chard (3.8 \pm 0.9 ). Regarding the "Grassy" intensity, green basil, and komatsuna species showed mean values significantly higher than the other microgreens (12.7 and 12.1, respectively). The intensity of "Heat" was highly perceived in cress $(12.6 \pm 0.6)$ as well as the "Sourness" attribute $(8.7 \pm 0.9)$. However, in the last case, the mean value was not statistically different from mibuna $(8.3 \pm 0.9)$ and amaranth $(7.3$ $\pm 1.1)$ species. Participants perceived the highest mean value of "Texture" intensity $(9.5 \pm 0.7)$ after tasting mibuna even if it was not statistically higher than coriander (9.1), green basil (8.9), tatsoi (8.7), and purslane (8.2).

As concerns the WTC (acceptability), values for acceptability of "Appearance" were extremely high and always greater (except for purslane) than those concerning "Texture" and "Flavor". The highest mean score for the "Appearance" was assessed for coriander (11.4 \pm 0.6$)$ that was 5.2 points higher than the lowest value $(6.2 \pm 0.8)$ expressed for cress. As for the "Flavor", the most preferred microgreens were Swiss chard (8.5 \pm 0.9$)$, coriander $(7.9 \pm 1.0)$, and purslane $(7.0 \pm 0.9)$ while the less preferred were cress $(3.9 \pm 0.8)$, mibuna $(3.6 \pm 0.8)$, and amaranth $(2.5 \pm 0.8)$. Finally, as concerns the overall eating quality, wide heterogeneity existed among microgreens, with both Swiss chard and coriander benefitting a very high score $(8.1 \pm 0.9)$ while on the opposite, amaranth showed the lowest score $(3.0 \pm 0.7)$. 
Table 2. Sensory attributes and acceptability items collected during the consumer test; mean and standard error of the nine sensory attributes and four acceptability items for the 12 microgreens species.

\begin{tabular}{|c|c|c|c|c|c|c|c|c|c|c|c|c|c|}
\hline & & \multicolumn{8}{|c|}{ Intensity } & \multicolumn{4}{|c|}{ Acceptability } \\
\hline & & Sweetness & Aroma & Astringency & Bitterness & Grassy & Heat & Sourness & Texture & Appearance & Flavor & Texture & Overall \\
\hline \multirow[t]{2}{*}{1} & Komatsuna & $3.1^{\mathrm{a}}$ & $8.1^{\mathrm{b}}$ & $3.9^{\mathrm{a}}$ & $6.5^{\mathrm{a}}$ & $12.1^{\mathrm{b}}$ & $5.6^{\mathrm{a}}$ & $4.5^{\mathrm{a}}$ & $7.7^{\mathrm{a}}$ & $8.8^{\mathrm{a}}$ & $6.6^{x}$ & $7.6^{\mathrm{a}}$ & $7.9^{b}$ \\
\hline & St. Err & 0.7 & 0.8 & 0.8 & 0.9 & 0.6 & 0.8 & 0.8 & 0.8 & 0.7 & 0.7 & 0.7 & 0.7 \\
\hline \multirow[t]{2}{*}{2} & Tatsoi & $2.7^{\mathrm{a}}$ & $5.8^{\mathrm{a}}$ & $6.2^{\mathrm{a}}$ & $6.0^{\mathrm{a}}$ & $10.2^{\mathrm{a}}$ & $4.6^{\mathrm{a}}$ & $4.4^{\mathrm{a}}$ & $8.7^{\mathrm{b}}$ & $9.6^{b}$ & $6.2^{x}$ & $7.3^{\mathrm{a}}$ & $7.5^{b}$ \\
\hline & St. Err & 0.5 & 0.8 & 0.8 & 0.8 & 0.7 & 0.9 & 0.7 & 0.5 & 0.7 & 0.7 & 0.7 & 0.7 \\
\hline \multirow[t]{2}{*}{3} & Pak Choi & $2.7^{\mathrm{a}}$ & $8.1^{b}$ & $5.0^{\mathrm{a}}$ & $6.5^{\mathrm{a}}$ & $10.3^{a}$ & $6.5^{\mathrm{a}}$ & $4.4^{\mathrm{a}}$ & $7.5^{\mathrm{a}}$ & $8.6^{\mathrm{a}}$ & $6.7^{x}$ & $7.7^{\mathrm{a}}$ & $7.9^{b}$ \\
\hline & St. Err & 0.5 & 0.7 & 0.7 & 0.9 & 0.6 & 0.8 & 0.6 & 0.6 & 0.9 & 0.8 & 0.8 & 0.8 \\
\hline \multirow[t]{2}{*}{4} & Mizuna & $3.8^{a}$ & $8.9^{b}$ & $5.6^{\mathrm{a}}$ & $6.0^{\mathrm{a}}$ & $9.8^{\mathrm{a}}$ & $6.9^{b}$ & $5.5^{\mathrm{a}}$ & $7.6^{\mathrm{a}}$ & $8.9^{\mathrm{a}}$ & $6.7^{x}$ & $8.3^{a}$ & $7.2^{b}$ \\
\hline & St. Err & 0.6 & 0.8 & 0.7 & 0.9 & 0.7 & 0.9 & 0.8 & 0.7 & 0.7 & 0.7 & 0.7 & 0.8 \\
\hline \multirow[t]{2}{*}{5} & Mibuna & $2.7^{\mathrm{a}}$ & $9.2^{b}$ & $7.5^{b}$ & $10.0^{b}$ & $10.9^{\mathrm{a}}$ & $10.6^{b}$ & $8.3^{b}$ & $9.5^{b}$ & $8.7^{\mathrm{a}}$ & $3.6^{\mathrm{w}}$ & $5.6^{\mathrm{a}}$ & $4.5^{\mathrm{a}}$ \\
\hline & St. Err & 0.6 & 0.9 & 0.9 & 0.8 & 0.8 & 0.9 & 0.9 & 0.7 & 0.7 & 0.8 & 0.8 & 0.8 \\
\hline \multirow[t]{2}{*}{6} & Cress & $2.3^{\mathrm{a}}$ & $10.0^{b}$ & $7.5^{b}$ & $9.0^{\mathrm{b}}$ & $9.5^{\mathrm{a}}$ & $12.6^{c}$ & $8.7^{b}$ & $7.8^{\mathrm{a}}$ & $6.2^{\mathrm{a}}$ & $3.9 \mathrm{w}$ & $5.1^{\mathrm{a}}$ & $4.8^{\mathrm{a}}$ \\
\hline & St. Err & 0.6 & 0.9 & 0.8 & 0.9 & 0.9 & 0.6 & 0.9 & 0.7 & 0.8 & 0.8 & 0.8 & 0.8 \\
\hline \multirow[t]{2}{*}{7} & Amaranth & $2.5^{\mathrm{a}}$ & $12.2^{\mathrm{C}}$ & $6.4^{\mathrm{a}}$ & $6.6^{\mathrm{a}}$ & $8.2^{\mathrm{a}}$ & $8.6^{\mathrm{b}}$ & $7.3^{\mathrm{b}}$ & $7.1^{\mathrm{a}}$ & $8.9^{a}$ & $2.5^{\mathrm{w}}$ & $4.9^{\mathrm{a}}$ & $3.0^{\mathrm{a}}$ \\
\hline & St. Err & 0.9 & 0.7 & 1.1 & 1.2 & 1.0 & 1.2 & 1.1 & 0.7 & 0.8 & 0.8 & 0.7 & 0.7 \\
\hline \multirow[t]{2}{*}{8} & Green Basil & $1.9^{\mathrm{a}}$ & $6.6^{\mathrm{a}}$ & $4.7^{\mathrm{a}}$ & $7.0^{\mathrm{a}}$ & $12.7^{b}$ & $4.7^{\mathrm{a}}$ & $2.7^{\mathrm{a}}$ & $8.9^{b}$ & $9.2^{\mathrm{a}}$ & $6.0^{\mathrm{w}}$ & $7.8^{\mathrm{a}}$ & $7.3^{b}$ \\
\hline & St. Err & 0.6 & 1.0 & 0.9 & 1.0 & 0.7 & 1.0 & 0.8 & 0.9 & 0.9 & 0.7 & 0.8 & 0.8 \\
\hline \multirow[t]{2}{*}{9} & Purple Basil & $3.8^{\mathrm{a}}$ & $3.4^{\mathrm{a}}$ & $3.0^{\mathrm{a}}$ & $5.1^{\mathrm{a}}$ & $8.2^{\mathrm{a}}$ & $2.8^{\mathrm{a}}$ & $3.5^{\mathrm{a}}$ & $7.9^{\mathrm{a}}$ & $9.1^{\mathrm{a}}$ & $5.0^{\mathrm{w}}$ & $7.2^{\mathrm{a}}$ & $6.0^{\mathrm{a}}$ \\
\hline & St. Err & 0.9 & 0.8 & 0.9 & 1.1 & 1.0 & 0.8 & 0.9 & 0.8 & 0.8 & 0.6 & 0.7 & 0.7 \\
\hline \multirow[t]{2}{*}{10} & Coriander & $2.9^{\mathrm{a}}$ & $13.0^{\mathrm{c}}$ & $6.3^{\mathrm{a}}$ & $6.3^{\mathrm{a}}$ & $9.2^{\mathrm{a}}$ & $9.7^{\mathrm{b}}$ & $4.3^{\mathrm{a}}$ & $9.1^{\mathrm{b}}$ & $11.4^{\mathrm{b}}$ & $7.9^{x}$ & $8.2^{\mathrm{a}}$ & $8.1^{b}$ \\
\hline & St. Err & 0.7 & 0.6 & 1.0 & 1.0 & 1.0 & 1.1 & 1.0 & 0.6 & 0.6 & 1.0 & 0.8 & 0.9 \\
\hline \multirow[t]{2}{*}{11} & Purslane & $2.4^{\mathrm{a}}$ & $10.4^{\mathrm{b}}$ & $5.2^{\mathrm{a}}$ & $7.4^{\mathrm{a}}$ & $11.1^{\mathrm{a}}$ & $6.5^{\mathrm{a}}$ & $4.9^{\mathrm{a}}$ & $8.2^{\mathrm{b}}$ & $6.6^{\mathrm{a}}$ & $7.0^{x}$ & $7.4^{\mathrm{a}}$ & $6.7^{\mathrm{a}}$ \\
\hline & St. Err & 0.7 & 0.8 & 0.8 & 0.8 & 0.7 & 1.1 & 0.9 & 0.8 & 0.9 & 0.9 & 0.8 & 1.0 \\
\hline \multirow[t]{2}{*}{12} & Swiss chard Chard & $5.9^{\mathrm{b}}$ & $5.6^{\mathrm{a}}$ & $3.7^{\mathrm{a}}$ & $3.8^{\mathrm{a}}$ & $9.1^{\mathrm{a}}$ & $3.6^{\mathrm{a}}$ & $2.3^{\mathrm{a}}$ & $4.8^{\mathrm{a}}$ & $8.5^{\mathrm{a}}$ & $8.5^{x}$ & $7.7^{\mathrm{a}}$ & $8.1^{b}$ \\
\hline & St. Err & 1.1 & 0.9 & 0.9 & 0.9 & 0.9 & 1.0 & 0.6 & 0.7 & 1.0 & 0.9 & 0.9 & 0.9 \\
\hline
\end{tabular}

Statistical differences were tested using ANOVA and Tukey's honestly significant difference (HSD) post hoc test. Different letters stand for statistically significant differences among microgreens at $p<0.05$. St. Err $=$ standard error. Highest score per each attribute or item is shown in bold. 


\subsection{Exploratory Factor Analysis (EFA) and PLS-SEM Measurement Model}

The analysis in this sub-section aimed to identify a possible relation between sensory attributes and consumer WTC (acceptability). In order to pursue this objective, an explanatory factor analysis (EFA) was carried out on the sensory attributes in order to identify the main latent sensory dimensions characterizing microgreens tasting. EFA identified two main latent constructs: factor loadings are shown in the second and third columns of Table 3, while the last column summarizes the fraction of the information of each sensory attribute not taken into account by the two factors (uniqueness). The first latent construct (Factor 1) was positively correlated with the Intensity of Astringency, Heat, and Sourness. These three sensory attributes were strictly associated with each-other in a unique dimension that was termed as "Sourness and Heat". Similarly, the second dimension was positively associated to the intensity of "Bitterness and Grassy", and (coherently) negatively with sweetness. Accordingly, this second dimension can be named as "Bitterness and Grassy".

Table 3. Exploratory Factor Analysis (EFA) using orthogonal (Varimax) rotation: factor loadings. EFA results on the nine sensory attributes of 12 microgreens species appraised through the untrained consumer test. Two main sensorial dimensions were successfully extracted from the nine sensory attributes. Factor loadings indicate the correlation between the attribute and the latent construct. Uniqueness shows the proportion of variance unaccounted for by the latent dimensions.

\begin{tabular}{lccc}
\hline & Factor 1 & Factor 2 & Uniqueness \\
\hline Intensity of Sweetness & & -0.7493 & 0.4307 \\
Intensity of Aroma & 0.5499 & & 0.6943 \\
Intensity of Astringency & 0.7121 & & 0.4403 \\
Intensity of Bitterness & & 0.5507 & 0.4233 \\
Intensity of Grassy & & 0.7074 & 0.4987 \\
Intensity of Heat & 0.8084 & & 0.3441 \\
Intensity of Sourness & 0.7691 & & 0.3839 \\
Intensity of Texture & 0.4321 & & 0.8106 \\
\hline
\end{tabular}

Loadings greater than $|0.4|$ are presented and used for interpretation. Bartlett test of sphericity: $\chi 2470.3$ ( $p$-value < 0.001). Kaiser-Meyer-Olkin measure of sampling adequacy: 0.77.

The identified relationships among sensory attributes, however, need to be confirmed through the measurement model of the PLS-SEM in which "Sourness and Heat" and "Bitterness and Grassy" constructs are ex-ante structured according to the EFA results. Moreover, the acceptability constructs will be developed on the basis of the information on the acceptability scores given by consumers for the four separate attributes: appearance, flavor, texture, and overall eating quality.

The PLS-SEM model, and its main results, are summarized in Figure 2. Measurement model output is shown in Table 4, presenting the standardized loadings interpretable as correlation between the latent constructs with each related sensory attribute. The results confirmed that "Sourness and Heat" dimension is indeed well associated with three sensory attributes, astringency (0.653), heat (0.511), and sourness (0.833), while the texture and aroma sensory attributes play a very limited role. On the other side, "Bitterness and Grassy" is mainly characterized by bitterness (0.725) and sweetness (-0853) sensory attributes rather than grassy (0.425). Similarly, the WTC construct is mainly characterized by flavor (0.936), texture (0.867), and the overall eating quality attributes $(0.952)$ while the role of the "appearance" in affecting the WTC seems relatively marginal (0.477). 


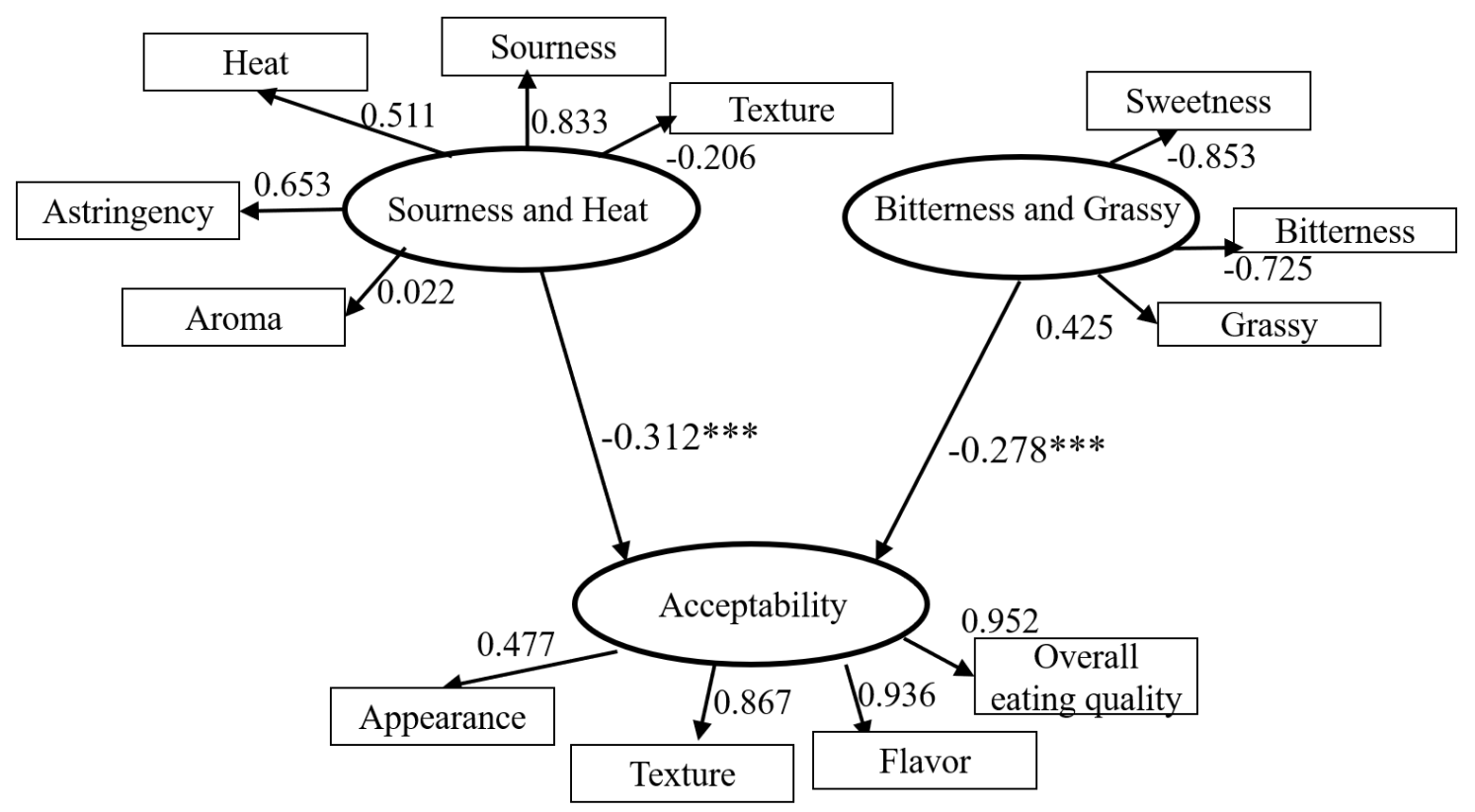

Figure 2. Partial least squares structural equation model (PLS-SEM) model and results. Each oval corresponds to a latent construct; each rectangle corresponds to a measured item or sensory attribute. The figure shows the magnitude and the significance of the relations between sensory attributes and consumer acceptability (path coefficients) and the correlation between the latent constructs with each related items or attribute (factor loadings). $\mathrm{R}^{2}$ of the model equal to 0.23 . Standardized path coefficients with absolute values around $|0.30|$ indicate a "medium" effect; ${ }^{* * *}$ significant at $p<0.001$.

Table 4. Measurement model of the PLS-SEM involving the nine sensory attributes of 12 microgreens species. Factor loadings indicate the correlation between the attribute and the latent construct.

\begin{tabular}{lccc}
\hline & Sourness and Heat & Bitterness and Grassy & WTC \\
\hline Intensity of Sweetness & 0.022 & -0.853 & \\
Intensity of Aroma & $\mathbf{0 . 6 5 3}$ & & \\
Intensity of Astringency & & $\mathbf{0 . 7 2 5}$ & \\
Intensity of Bitterness & $\mathbf{0 . 5 1 1}$ & $\mathbf{0 . 4 2 5}$ & \\
Intensity of Grassy & $\mathbf{0 . 8 3 3}$ & & \\
Intensity of Heat & -0.206 & $\mathbf{0 . 4 7 7}$ \\
Intensity of Sourness & & & $\mathbf{0 . 9 3 6}$ \\
Intensity of Texture & & $\mathbf{0 . 8 6 7}$ \\
\hline Acceptability of Appearance & & $\mathbf{0 . 9 5 2}$ \\
Acceptability of Flavor & & \\
Acceptability of Texture & & \\
Acceptability of Overall eating quality & & & \\
\hline
\end{tabular}

Loadings greater than $|0.4|$ (bold) are considered to contribute substantially to that component.

Figure 3 plots for each of the 12 microgreens the mean and the $95 \%$ confidence intervals of the three latent constructs as calculated by PLS-SEM. A preliminary examination of the figure indicates that Swiss chard and coriander scored the higher level of acceptability while for almost all the considered microgreens, a higher (lower) value of acceptability is associated to a lower (higher) value of "Sourness and Heat". The relation between "Bitterness and Grassy" and acceptability seems a little bit less direct and deserve a specific examination through the estimated PLS-SEM standardized path coefficients. Indeed, they indicate the existing statistical relations between sensory attributes and consumer acceptability. The results in Figure 2 showed that both the sensorial dimensions negatively affected the consumers WTC of microgreens (path coefficient of sourness and heat equal to -0.312 ; 
path coefficient of bitterness and grassy equal to -0.278). In other words, the acceptability (WTC) of microgreens decreased when the perceived sensorial intensity of bitterness and sourness increased.

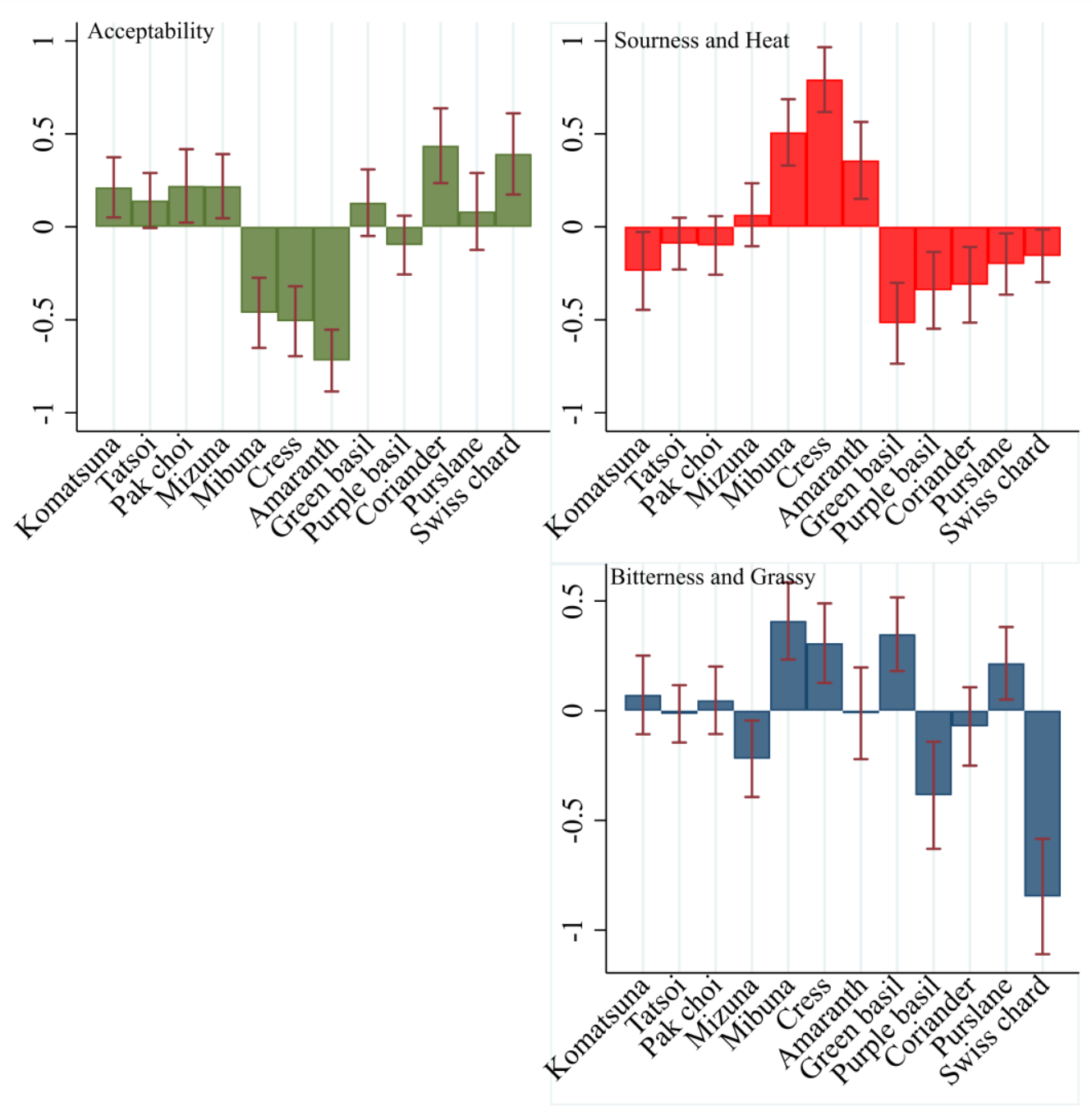

Figure 3. Mean and the $95 \%$ confidence intervals of the three latent constructs (Acceptability; Bitterness and Grassy; Sourness and Heat) for the 12 microgreens species as calculated by PLS-SEM. All latent constructs are standardized with a mean of 0 and a standard deviation of 1 . Swiss chard and coriander scored the higher level of acceptability while for almost all the considered microgreens, a higher (lower) value of acceptability is associated to a lower (higher) value of "Sourness and Heat".

Figure 4 represents graphically the estimated relations between the two main sensory dimensions experienced by our consumer sample group with the acceptability of microgreens species. In particular, Swiss chard (indicated with number 12 in Figure 4) is the most appreciated by participants followed by coriander (indicated with number 10). Both species are characterized by low score of intensity in the two main sensorial dimensions. Conversely, mibuna, cress, and amaranth (numbers 5, 6, and 7 in Figure 2) are the less appreciated ones, being characterized by the highest intensity of "Bitterness and Grassy" and "Sourness and Heat". 


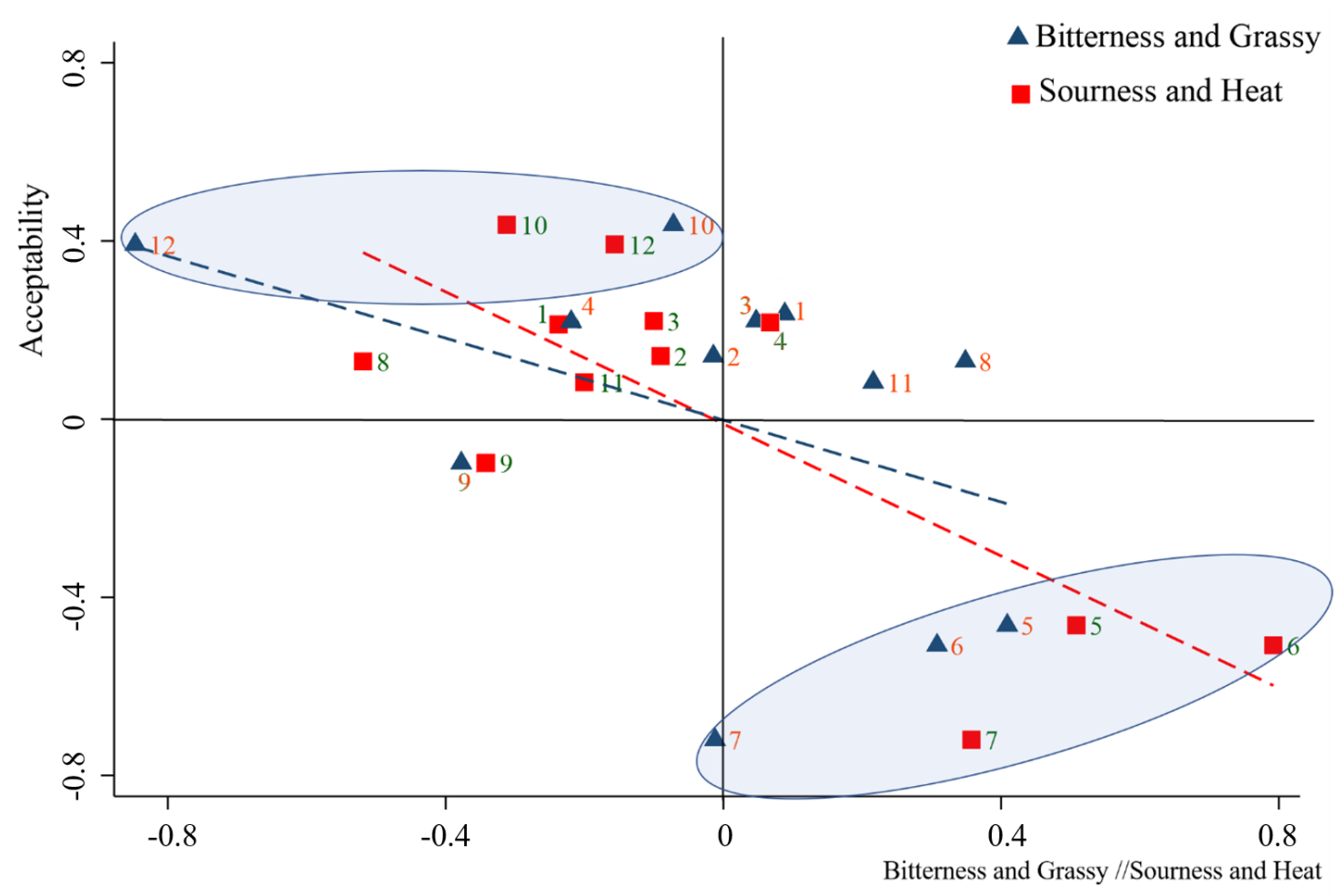

Figure 4. Estimated relations between the two main sensorial dimension of microgreens and the overall consumer acceptability. In this figure the $x$-axis represents scores of both latent factors representing the sensorial dimensions (Bitterness and Grassy; Sourness and Heat) while the $y$-axis represents the score on consumer's acceptability. All latent constructs are standardized with a mean of 0 and a standard deviation of 1. 1. Komatsuna; 2. Tatsoi; 3. Pak choi; 4. Mizuna; 5. Mibuna; 6. Cress; 7. Amaranth; 8. Green basil; 9. Purple basil; 10. Coriander; 11. Purslane; 12. Swiss chard.

\section{Discussion}

The sensory attributes of 12 microgreens species were analyzed through a consumer test, and based on the experimental data, a specific PLS-SEM model was developed to link sensorial attributes to consumer acceptability.

Our findings showed that consumer acceptability of the 12 considered microgreens was largely influenced by their sensory characteristics as well as by their visual appearance. It is well documented in the literature that the appearance of food products massively influences consumer choices, providing in the case of vegetables, direct quality signals to the consumer on their naturalness and freshness [31]. In our study, appearance scores of the assessed microgreens were consistently greater (except for purslane) than those concerning texture and flavor. This outcome is not completely unexpected, since recent studies attributed high scores of microgreens' acceptability to appearance [8,29]. Additionally, our results provide substantial evidence of the high potential for microgreens to be used as garnishes in enhancing the overall visual appearance of prepared meals. Nonetheless, Michell et al. [8] stressed the importance of using microgreens in a balanced way, considering their impact on the overall taste of the meal. Indeed, once tasted, the overall acceptability of the analyzed microgreens mainly depends on some specific sensory attributes. This result is in line with the findings of Tan et al. [6], who indicated that broccoli microgreens grown in diverse methods, had different taste, smell, and appearance, which contributed to consumer perception of microgreens. Indeed, flavor-related characteristics predict the best the consumer preferences for overall eating quality.

Therefore, sensory characteristics play a crucial role in affecting consumer preferences. Previous literature indicated how the latter strongly depends on the biochemical composition of microgreens which, in turn, is ruled by the genotype, developmental stage, or maturity level of the plant, pre-harvest 
conditions and finally by the post-harvest treatments. For instance, Talavera-Bianchi [25] concluded that by analyzing the sensory characteristics of pak choi, that many attributes such as crispness, texture, green-grassy/leafy, and bitterness had lower intensities in earlier stages than in older plants. Similarly, Oruna-Concha et al. [27] showed that coriander as microgreens contained significantly higher concentrations of phenolic compounds and terpenes and a more intense bitter/sweet taste compared to the mature stage. Finally, Dalal et al. [47] demonstrated that sensory characteristics of microgreens are heavily influenced by post-harvest and packaging treatments showing a progressive decrease of acceptability due to change in sensory attributes during storage.

In order to consider the above-mentioned framework, all the 12 microgreens species were tasted by consumers at the same stage of development (emergence of the first two true leaves), thereby our analyses focused on analyzing explicitly the influence of genotype. Of the 12 assessed microgreens species, five showed a satisfactory (equal or greater than 7.5) overall acceptability (Swiss chard, coriander, komatsuna, pak choi, tatsoi), while only three (amaranth, mibuna, and cress) recorded a score completely unsatisfactory (lower than 5). Based on the work of Kyriacou et al. [9,12], amaranth, mibuna, and cress are rich in polyphenols that confer the heat intensity and the astringency level. According the same the authors, amaranth is rich in $\mathrm{Mg}$ and cress is rich in vitamin $\mathrm{C}$, which is behind the metallic taste in the mouth. Moreover, mibuna and cress are rich in sulphate that is responsible of the bitterness. These attributes are the cause of the low overall acceptability of these three species (score $<5)$. Our statistical analysis indicated that the observed differences in microgreens acceptability depended on two main sensory dimensions experienced through the consumer test: (i) astringency/sourness and (ii) bitterness. Particularly, the lower the astringency, sourness, and bitterness, the higher the consumer acceptability of microgreens.

Although there are only a few studies about consumer acceptability of microgreens, these results are consistent with previous studies in which the bitterness and astringency attributes represent important factors for consumers to reject vegetables [11,28]. Appreciating the nutritive attributes of quality, necessitates that consumers familiarize their perception of palatability to encompass fruits and vegetables of conventionally less agreeable, more astringent, bitter, and sour sensory profile [48]. High concentrations of chemopreventive phytonutrients tend to characterize foods less pleasant or familiar in taste, which constitutes a barrier to more diversifying the genetic basis of resources utilized for food production [49]. For instance, Senevirathne et al. [28] evaluated the sensory characteristics of 10 microgreens species and while lettuce and carrot received the highest preference, radish that is particularly bitter and astringent due to the glucosinolates and polyphenols compounds, received the lowest preference. Similarly, in our consumer test, mibuna and cress showed the lowest acceptance and the highest level of astringency and bitterness. Conversely, Swiss chard, as well as coriander, which showed low levels of bitterness and astringency, were the most appreciated by consumers. These results can be compared with those reported by Xiao et al. [11] that identified the same negative relation between the overall eating quality of microgreens with some sensory characteristics connected to the high phenolic content, that are the same to what we identified: sourness, astringency, and bitterness. In particular, authors identified the bull's blood beet (characterized by the lowest intensity in sourness, astringency, and bitterness) as the most appreciated microgreens by the consumer test while peppercress (characterized by the highest intensity in sourness, astringency, and bitterness) had the lowest acceptability.

Moreover, several studies have demonstrated that consumers in Western countries have a generalized aversion to food with a bitter taste [21]. The main explanations behind this aversion seem to be associated to the human evolution process, since bitterness in nature indicates possibly dangerous ingredients to health [50]. However, bitterness as well as astringency are also associated, to various biochemicals that are beneficial to human health, contemporarily with consumer demand for healthy products increasing over time [51]. Consumer interest in healthy food can be mostly explained by the exponential growth of lifestyle related diseases (e.g., obesity, diabetes) specifically dietary related [20]. To this extent, microgreens can be considered as ideal candidates for meeting consumer request for 
healthier eating beyond their biochemical compounds content, and rather their perceived naturalness. The latter is explained by the fact that microgreens are grown and marketed without the use of synthetic substances that are considered by consumers to pose health risks. Microgreens perceived naturalness depends also on their minimal processing requirements, while human interventions, contact, and intense processing stages may reduce the perceived naturalness, and consequently healthiness of food [52]. These attributes, if well communicated to consumers, may contribute significantly to the market success of microgreens.

\section{Conclusions}

This study investigated whether sensory attributes and visual appearance affect consumer preference for microgreens and their willingness to consume them. Acceptability and sensory attributes of 12 microgreens genotypes were assessed through a consumer test. The results indicate that the visual appearance of microgreens has high consumer appreciation, but the overall acceptability was mainly determined by flavor and texture. In particular, the lower the astringency, sourness, and bitterness characteristics, the higher the consumer acceptability of microgreens. Among the 12 examined species, mibuna and cress scored the lowest acceptance by consumers, while Swiss chard and coriander were the most appreciated, and thus represent good aspirants for being introduced in Western country markets. In addition, both Swiss chard and coriander have been identified by previous literature as good dietary source of phenolic antioxidants [53,54].

Although this study has some limitations such as the small size of the consumer sample in addition to the fact that specific characteristics such as cultural differences or color blindness are not taken into account, the results contributed to the knowledge regarding consumer acceptability of microgreens by exposing important implications related to the selection and commercialization of new microgreens species. Moreover, the empirical approach described in this study may be easily used for future comparison or extended by inclusion of other microgreens characteristics. Further studies could investigate in detail the relationship between sensory attributes and chemical composition of microgreens, as well as to our understanding of how phenological stages of the product may affect consumer perception and preferences. Moreover, future studies should be directed toward studying consumer knowledge of the healthy and nutritional characteristics of microgreens and how the acceptability can be affected by the information level of the consumer. Indeed, providing information about the food product characteristics represents one of the key instruments for increasing consumer interest and positive perception of the product. It is expected that providing specific information on microgreens' culinary use and health-benefiting phytonutrient content may broaden consumer preferences for microgreens and subsequently increase their overall acceptability.

Supplementary Materials: The following are available online at http:/www.mdpi.com/2073-4395/10/7/1043/s1, Supplementary Table S1: Common and scientific name, cultivar, producing company, and the growing cycle of the 12 microgreens species grown in a controlled walk-through climate chamber (phytotron).

Author Contributions: Conceptualization, Y.R., F.C., L.C.; methodology, F.C., L.C., M.R.; formal analysis, F.C., M.R.; investigation, F.C., M.R.; resources, Y.R. and S.D.P.; data curation, F.C., M.R.; writing-original draft preparation, F.C., M.R., C.E.-N., Y.R.; writing-review and editing, F.C., M.R., L.C., C.E.-N., M.C.K. and Y.R.; supervision, F.C., L.C.; funding acquisition, S.D.P. and Y.R. All authors have read and agreed to the published version of the manuscript.

Funding: This research received no external funding.

Acknowledgments: The authors are grateful to Antonio Pannico and Maria Giordano for their technical assistance in the phytotron plant growth chamber experiment and the laboratory.

Conflicts of Interest: The authors declare no conflict of interest. 


\section{References}

1. Kyriacou, M.C.; Rouphael, Y.; Di Gioia, F.; Kyratzis, A.; Serio, F.; Renna, M.; De Pascale, S.; Santamaria, P. Micro-scale vegetable production and the rise of microgreens. Trends Food Sci. Technol. 2016, 57, $103-115$. [CrossRef]

2. Brentlinger, D.J. New trends in hydroponic crop production in the US. In Proceedings of the International Conference and Exhibition on Soilless Culture: ICESC 2005, Singapore, 5-8 September 2005; Volume 742, pp. 31-33. [CrossRef]

3. Kyriacou, M.C.; De Pascale, S.; Kyratzis, A.; Rouphael, Y. Microgreens as a component of space life support systems: A cornucopia of functional food. Front. Plant Sci. 2017, 8, 1587. [CrossRef]

4. Di Gioia, F.; Renna, M.; Santamaria, P. Sprouts, microgreens and baby leaf vegetables. In Minimally Processed Refrigerated Fruits and Vegetables; Springer: Boston, MA, USA, 2017; pp. 403-432. [CrossRef]

5. Renna, M.; Di Gioia, F.; Leoni, B.; Mininni, C.; Santamaria, P. Culinary Assessment of Self-Produced Microgreens as Basic Ingredients in Sweet and Savory Dishes. J. Culinary Sci. Technol. 2017, 15, 126-142. [CrossRef]

6. Tan, L.; Nuffer, H.; Feng, J.; Kwan, S.H.; Chen, H.; Tong, X.; Kong, L. Antioxidant properties and sensory evaluation of microgreens from commercial and local farms. Food Sci. Human Wellness 2020, 9, 45-51. [CrossRef]

7. Turner, E.R.; Luo, Y.; Buchanan, R.L. Microgreen nutrition, food safety, and shelf life: A review. J. Food Sci. 2020, 85, 870-882. [CrossRef] [PubMed]

8. Michell, K.A.; Isweiri, H.; Newman, S.E.; Bunning, M.; Bellows, L.L.; Dinges, M.M.; Prenni, J.E. Microgreens: Consumer sensory perception and acceptance of an emerging functional food crop. J. Food Sci. 2020, 85, 926-935. [CrossRef]

9. Kyriacou, M.C.; El-Nakhel, C.; Graziani, G.; Pannico, A.; Soteriou, G.A.; Giordano, M.; Ritieni, A.; De Pascale, S.; Rouphael, Y. Functional quality in novel food sources: Genotypic variation in the nutritive and phytochemical composition of thirteen microgreens species. Food Chem. 2019, 277, 107-118. [CrossRef]

10. Pannico, A.; El-Nakhel, C.; Graziani, G.; Kyriacou, M.C.; Giordano, M.; Soteriou, G.A.; Zarrelli, A.; Ritieni, A.; De Pascale, S.; Rouphael, Y. Selenium biofortification impacts the nutritive value, polyphenolic content, and bioactive constitution of variable microgreens species. Antioxidants 2020, 9, 272. [CrossRef] [PubMed]

11. Xiao, Z.; Lester, G.E.; Park, E.; Saftner, R.A.; Luo, Y.; Wang, Q. Evaluation and correlation of sensory attributes and chemical compositions of emerging fresh produce: Microgreens. Postharvest Biol. Technol. 2015, 110, 140-148. [CrossRef]

12. Kyriacou, M.C.; El-Nakhel, C.; Pannico, A.; Graziani, G.; Soteriou, G.A.; Giordano, M.; Zarrelli, A.; Ritieni, A.; De Pascale, S.; Rouphael, Y. Genotype-specific modulatory effects of select spectral bandwidths on the nutritive and phytochemical composition of microgreens. Front. Plant Sci. 2019, 10, 1501. [CrossRef]

13. El-Nakhel, C.; Pannico, A.; Graziani, G.; Kyriacou, M.C.; Giordano, M.; Ritieni, A.; De Pascale, S.; Rouphael, Y. Variation in macronutrient content, phytochemical constitution and in vitro antioxidant capacity of green and red butterhead lettuce dictated by different developmental stages of harvest maturity. Antioxidants 2020, 9, 300. [CrossRef] [PubMed]

14. El-Nakhel, C.; Pannico, A.; Kyriacou, M.C.; Giordano, M.; De Pascale, S.; Rouphael, Y. Macronutrient deprivation eustress elicits differential secondary metabolites in red and green-pigmented butterhead lettuce grown in a closed soilless system. J. Sci. Food Agric. 2019, 99, 6962-6972. [CrossRef]

15. Kyriacou, M.C.; El-Nakhel, C.; Pannico, A.; Graziani, G.; Soteriou, G.A.; Giordano, M.; Palladino, M.; Ritieni, A.; De Pascale, S.; Rouphael, Y. Phenolic constitution, phytochemical and macronutrient content in three species of microgreens as modulated by natural fiber and synthetic substrates. Antioxidants 2020, 9, 252. [CrossRef] [PubMed]

16. Caracciolo, F.; Lombardi, P. A new-institutional framework to explore the trade-off between agriculture, environment and landscape. Econ. Policy Energy Environ. 2012, 3, 135-154.

17. Del Giudice, T.; Stranieri, S.; Caracciolo, F.; Ricci, E.C.; Cembalo, L.; Banterle, A.; Cicia, G. Corporate Social Responsibility certifications influence consumer preferences and seafood market price. J. Clean. Prod. 2018, 178, 526-533. [CrossRef]

18. Panico, T.; Del Giudice, T.; Caracciolo, F. Quality dimensions and consumer preferences: A choice experiment in the Italian extra-virgin olive oil market. Agric. Econ. Rev. 2014, 15, 100-112. 
19. Colantuoni, F.; Cicia, G.; Del Giudice, T.; Lass, D.; Caracciolo, F.; Lombardi, P. Heterogeneous preferences for domestic fresh produce: Evidence from German and Italian early potato markets. Agribusiness 2016, 32, 512-530. [CrossRef]

20. Caracciolo, F.; Vecchio, R.; Lerro, M.; Migliore, G.; Schifani, G.; Cembalo, L. Natural versus enriched food: Evidence from a laboratory experiment with chewing gum. Food Res. Int. 2019, 122, 87-95. [CrossRef]

21. Cavallo, C.; Caracciolo, F.; Cicia, G.; Del Giudice, T. Extra-virgin olive oil: Are consumers provided with the sensory quality they want? A hedonic price model with sensory attributes. J. Sci. Food Agric. 2018, 98, 1591-1598. [CrossRef]

22. Barrett, D.M.; Beaulieu, J.C.; Shewfelt, R. Color, flavor, texture, and nutritional quality of fresh-cut fruits and vegetables: Desirable levels, instrumental and sensory measurement, and the effects of processing. Critical Rev. Food Sci. Nutr. 2010, 50, 369-389. [CrossRef]

23. Van der Laan, L.N.; De Ridder, D.T.; Viergever, M.A.; Smeets, P.A. Appearance matters: Neural correlates of food choice and packaging aesthetics. PLoS ONE 2012, 7, e41738. [CrossRef] [PubMed]

24. Suki, N.M. Consumer environmental concern and green product purchase in Malaysia: Structural effects of consumption values. J. Cleaner Prod. 2016, 132, 204-214. [CrossRef]

25. Talavera-Bianchi, M.; Adhikari, K.; Chambers IV, E.; Carey, E.E.; Chambers, D.H. Relation between developmental stage, sensory properties, and volatile content of organically and conventionally grown pac choi (Brassica rapa var. Mei Qing Choi). J. Food Sci. 2010, 75, S173-S181. [CrossRef] [PubMed]

26. Ebert, A.W.; Wu, T.H.; Yang, R.Y. Amaranth sprouts and microgreens-a homestead vegetable production option to enhance food and nutrition security in the rural-urban continuum. In Proceedings of the Regional Symposium on Sustaining Small-Scale Vegetable Production and Marketing Systems for Food and Nutrition Security (SEAVEG 2014), Bangkok, Thailand, 25-27 February 2014; pp. 25-27.

27. Oruna-Concha, M.J.; Lignou, S.; Feeney, E.L.; Beegan, K.; Kenny, O.; Harbourne, N. Investigating the phytochemical, flavour and sensory attributes of mature and microgreen coriander (Coriandrum sativum). In Flavour Science; Siegmund, B., Leitner, E., Eds.; Verlag der Technischen Universität Graz: Graz, Austria, 2018.

28. Senevirathne, G.I.; Gama-Arachchige, N.S.; Karunaratne, A.M. Germination, harvesting stage, antioxidant activity and consumer acceptance of ten microgreens. Ceylon J. Sci. 2019, 48, 91-96. [CrossRef]

29. Guijarro-Real, C.; Prohens, J.; Rodríguez-Burruezo, A.; Fita, A. Consumers acceptance and volatile profile of wall rocket (Diplotaxis erucoides). Food Res. Int. 2020, 132, 109008. [CrossRef]

30. Lombardi, A.; Caracciolo, F.; Cembalo, L.; Lerro, M.; Lombardi, P. How does corporate social responsibility in the food industry matter. New Medit. 2015, 14, 2-9.

31. Jürkenbeck, K.; Meyerding, S.G.H. Preferences for fresh tomatoes with a focus on young consumers in Germany-Choice-experiment and latent class analysis. Eur. J. Hortic. Sci. 2019, 84, 325-331. [CrossRef]

32. Resurreccion, A.V.A. Consumer sensory testing for food product development. In Developing New Food Products for a Changing Marketplace; Brody, A.L., Lord, J.B., Eds.; CRC Press: Boca Raton, FL, USA, 2007.

33. Gotor, E.; Alercia, A.; Rao, V.R.; Watts, J.; Caracciolo, F. The scientific information activity of bioversity international: The descriptor lists. Genet. Resour. Crop Evol. 2008, 55, 757-772. [CrossRef]

34. Wold, H. Path models with latent variables: The NIPALS approach. In Quantitative sociology; Academic Press: Cambridge, MA, USA, 1975; pp. 307-357. [CrossRef]

35. Lohmöller, J.B. Predictive vs. structural modeling: PLS vs. ML. In Latent Variable Path Modeling with Partial Least Squares; Springer: Berlin/Heidelberg, Germany, 1989. [CrossRef]

36. Marmaya, N.H.; Zakaria, Z.; Desa, M.N.M. Gen Y consumers' intention to purchase halal food in Malaysia: A PLS-SEM approach. J. Islamic Mark. 2019. [CrossRef]

37. Pérez-Villarreal, H.H.; Martínez-Ruiz, M.P.; Izquierdo-Yusta, A. Testing model of purchase intention for fast food in mexico: How do consumers react to food values, positive anticipated emotions, attitude toward the brand, and attitude toward eating hamburgers? Foods 2019, 8, 369. [CrossRef]

38. Ting, H.; Tan, S.R.; John, A.N. Consumption intention toward ethnic food: Determinants of Dayak food choice by Malaysians. J. Ethnic Foods 2017, 4, 21-27. [CrossRef]

39. Ting, H.; de Run, E.C.; Cheah, J.H.; Chuah, F. Food neophobia and ethnic food consumption intention: An extension of the theory of planned behaviour. Br. Food J. 2016, 118, 2781-2797. [CrossRef]

40. Gakobo, T.W.; Jere, M.G. An application of the theory of planned behaviour to predict intention to consume African indigenous foods in Kenya. Br. Food J. 2016, 118, 1268-1280. [CrossRef] 
41. Zhu, X.; Wei, Y.; Lai, Y.; Li, Y.; Zhong, S.; Dai, C. Empirical analysis of the driving factors of china's 'land finance' mechanism using soft budget constraint theory and the PLS-SEM model. Sustainability 2019, 11, 742. [CrossRef]

42. Hair, J.F., Jr.; Sarstedt, M.; Hopkins, L.; Kuppelwieser, V.G. Partial least squares structural equation modeling (PLS-SEM). Eur. Bus. Rev. 2014, 26, 106-121.

43. Hair, J.F.; Ringle, C.M.; Sarstedt, M. PLS-SEM: Indeed a silver bullet. J. Mark. Theory Pract. 2011, 19, $139-152$. [CrossRef]

44. Garson, G.D. Partial Least Squares: Regression and Structural Equation Models; Statistical Associates Publishers: Asheboro, NC, USA, 2016.

45. Venugopal, A.; Shukla, D. Identifying consumers' engagement with renewable energy. Bus. Strategy Environ. 2019, 28, 53-63. [CrossRef]

46. Chin, W.W. The partial least squares approach to structural equation modeling. Mod. Methods Bus. Res. 1998, 295, 295-336.

47. Dalal, N.; Siddiqui, S.; Phogat, N. Evaluation of effects of chemical treatments on sensory attributes of sunflower microgreens with storage. J. Pharmacogn. Phytochem. 2020, 9, 439-443.

48. Kyriacou, M.C.; Raphael, Y. Towards a new definition of quality for fresh fruits and vegetables. Sci. Hortic. 2018, 234, 463-469. [CrossRef]

49. Drewnowski, A.; Gomez-Carneros, C. Bitter taste, phytonutrients, and the consumer: A review. Am. J. Clin. Nutr. 2000, 72, 1424-1435. [CrossRef] [PubMed]

50. Caracciolo, F.; Cavallo, C.; Del Giudice, T.; Panico, T.; Vecchio, R.; Cicia, G. Consumers (Dis) Preference for bitterness in extra virgin olive oil: A field experiment. Int. J. Food Syst. Dyn. 2020, 11, 14-25.

51. Migliore, G.; Cembalo, L.; Caracciolo, F.; Schifani, G. Organic consumption and consumer participation in food community networks. New Medit. 2012, 11, 46-48.

52. Rozin, P.; Spranca, M.; Krieger, Z.; Neuhaus, R.; Surillo, D.; Swerdlin, A.; Wood, K. Preference for natural: Instrumental and ideational/moral motivations, and the contrast between foods and medicines. Appetite 2004, 43, 147-154. [CrossRef] [PubMed]

53. Pyo, Y.H.; Lee, T.C.; Logendra, L.; Rosen, R.T. Antioxidant activity and phenolic compounds of Swiss chard (Beta vulgaris subspecies cycla) extracts. Food Chem. 2004, 85, 19-26. [CrossRef]

54. Wangensteen, H.; Samuelsen, A.B.; Malterud, K.E. Antioxidant activity in extracts from coriander. Food Chem. 2004, 88, 293-297. [CrossRef]

(C) 2020 by the authors. Licensee MDPI, Basel, Switzerland. This article is an open access article distributed under the terms and conditions of the Creative Commons Attribution (CC BY) license (http://creativecommons.org/licenses/by/4.0/). 